$12-1-2018$

\title{
Foam materials with controllable pore structure prepared from nanofibrillated cellulose with addition of alcohols
}

Jinbao Li

Te Song

Huijuan Xiu

Meiyun Zhang

Rui Cheng

See next page for additional authors

How does access to this work benefit you? Let us know!

Follow this and additional works at: https://commons.und.edu/che-fac

Part of the Chemical Engineering Commons

\section{Recommended Citation}

Jinbao Li, Te Song, Huijuan Xiu, et al.. "Foam materials with controllable pore structure prepared from nanofibrillated cellulose with addition of alcohols" (2018). Chemical Engineering Faculty Publications. 8. https://commons.und.edu/che-fac/8

This Article is brought to you for free and open access by the Department of Chemical Engineering at UND Scholarly Commons. It has been accepted for inclusion in Chemical Engineering Faculty Publications by an authorized administrator of UND Scholarly Commons. For more information, please contact und.commons@library.und.edu. 


\section{Authors}

Jinbao Li, Te Song, Huijuan Xiu, Meiyun Zhang, Rui Cheng, Qiang Liu, Xuefei Zhang, Evguenii Kozliak, and Yun Ji

This article is available at UND Scholarly Commons: https://commons.und.edu/che-fac/8 


\title{
Foam materials with controllable pore structure prepared from nanofibrillated cellulose with addition of alcohols
}

JinbaoLi ${ }^{\mathrm{ab}}$ TeSong $^{\mathrm{a} H u i j u a n X i u^{\mathrm{ac}} \text { MeiyunZhang }}{ }^{\mathrm{a}}$ RuiCheng ${ }^{\mathrm{a}}$ QiangLiu ${ }^{\mathrm{a}}$ XuefeiZhang ${ }^{\mathrm{d}}$ EvgueniiKozliak $^{\mathrm{e}}$ YunJi $^{\mathrm{d}}$

\author{
${ }^{a}$ National Experimental Teaching Demonstration Center for Light Chemical Engineering, Shaanxi \\ University of Science \& Technology, Xian, 710021, China \\ bState Key Laboratory of Pulp and Paper Engineering, South China University of Technology, \\ Guangzhou, 510640, China \\ 'Shaanxi Province Key Lab of Papermaking Technology and Specialty Paper, Xian, 710021, \\ China \\ dDepartment of Chemical Engineering, University of North Dakota, Grand Forks, ND, 58202, USA \\ eDepartment of Chemistry, University of North Dakota, Grand Forks, ND, 58202, USA
}

\begin{abstract}
Low-density foams based on nanofibrillated cellulose (NFC) made from Pinus massoniane softwood pulp were prepared from NFC aqueous suspensions containing one of four $\mathrm{C} 2-\mathrm{C} 4$ alcohols followed by freeze-drying, with the goal of controlling their pore structure and reducing the shrink rate. The foams prepared from NFC suspensions containing ethanol, isopropanol and $n$-butanol exhibited highly porous structures with a honeycomb-like cellular texture featuring well-defined "cell walls" between the layers. By contrast, the tert-butanol/NFC foam featured a higher number of smaller size pores with irregular shape. The foams prepared by freezing at $-196^{\circ} \mathrm{C}$ with ethanol also revealed small size pores, with no layered pore structure. The results obtained suggested that freeze-drying could be used to control the key foam parameters by adding different alcohols into an NFC suspension and adjusting the freezing temperature. Combining the obtained information, a possible formation mechanism was proposed. The microstructure, density, porosity, shrinkage, mechanical properties and thermal properties of NFC foams were determined. The obtained NFC foams feature low shrinkage upon formation and thermal conductivity. Smaller Young's modulus and energy absorption yet similar yield stress values compared to the blank indicate that the freeze-drying in the presence of alcohols tends to generate "soft" foams.
\end{abstract}

\section{Keywords}

Nanofibrillated cellulose, Freeze-drying, Alcohols, Porous foams

\section{Introduction}

For near two decades, nanocellulose and its modified derivatives have been widely used as reinforcement materials in polymeric nanocomposites (Malainine et al., 2005; Nakagaito and Yano, 2004; Samir et al., 2004; Svagan et al., 2007). Development of biodegradable, renewable and recyclable foam 
materials has gained a strong interest due to the increasing environmental concerns and depletion of petroleum (Frech, 2002). Cellulose, one of the most abundant, low cost, highly accessible, readily treatable and renewable bioresources, has become a promising alternative to manufacture value-added products (Klemm et al., 2005; Wang et al., 2006). Therefore researchers become increasingly interested in exploiting the unique physical properties of cellulose, especially nanocellulose (De France et al., 2017). Its density is low and its Young's modulus and tensile strength are remarkably high, approaching those of advanced synthetic analogs.

In this respect, nanocellulose based foam has been considered as one of the most promising biodegradable alternatives to its petrochemical analogs (Svagan et al., 2008). Nanocellulose based foam has demonstrated strong mechanical strength in spite of its light weight and high porosity, thus showing potential for applications in packing, acoustic absorption, use as filters, manufacturing thermal insulation materials, tissue engineering, etc.

In the past, research in this area was mainly focused either on raw materials such as nanocrystalline cellulose (Dash et al., 2012; De France et al., 2017) and nanofibrillated cellulose (Ali and Gibson, 2013; De France et al., 2017; Martoïa et al., 2016; Sehaqui et al., 2011a, Sehaqui et al., 2010) or on their applications as strengthening agents to improve the quality of foams based on starch (Svagan et al., 2011, Svagan et al., 2010, Svagan et al., 2008, Svagan et al., 2007), polyvinyl alcohol (Liu and Yan, 2014), polylactate (Dlouhá et al., 2014) and polyurethane (Li and Ragauskas, 2012).

The issue hindering the application of NFC based foams is their poorly reproducible production. Traditional foam forming protocols are based on suspending a chemical foaming agent in a suitable medium, followed by mechanical stirring and physical foaming. Unfortunately, this method is not applicable to NFC suspensions whose preparation requires a high water content. However, this issue can be readily addressed by switching to freeze-drying protocols.

Freeze-drying (also called lyophilization) (Nireesha et al., 2013), a low-temperature dehydration technique that removes (by sublimation) the water present in a sample after its freezing, can be used to prepare foam materials (Nakamatsu et al., 2006; Sehaqui et al., 2010; Svagan et al., 2008). Building on the earlier published work, freeze-drying has been considered a simple, efficient and relatively inexpensive method to prepare highly ordered porous foams with controlled structure (Deville, 2013, Deville, 2010; Deville et al., 2009; Li et al., 2012; O’Brien et al., 2004).

During the freeze-drying process, the unidirectional growth of ice crystals upon sample freezing followed by the sublimation of ice crystals results in the formation of a highly ordered porous foam with unidirectional channels (Dash et al., 2012; Lee and Deng, 2011; Martoïa et al., 2016). The ice crystals forming during the freezing step constitute a "template" for the cell wall formation. This templating feature, 
due to the readily established control of the ice freezing rate, enables the opportunity of tailoring the pore size of the foam to be formed (Svagan et al., 2010).

However, low freezing rate is known to generate significant shrinkage during the freeze-drying process resulting in production of high density, low porosity foams. Even though conducting the process in liquid nitrogen, i.e., at a high freezing rate, resulted in low density and high porosity foams (Ali and Gibson, 2013; Martoïa et al., 2016), this process is not easy to conduct, and a rather long drying time is required. In addition, the traditional freeze-drying (lyophilization) process was performed with simple aqueous solutions, with no other solvents. Therefore, when water was sublimed from the solid phase during the drying process, a significant shrinkage occurred resulting in an uneven pore size distribution and poor mechanical properties of the foams. Thus, it is necessary to seek new ways to modify the freeze-drying protocol to control the foam microstructure readily and effectively.

Recently, freeze-drying in the presence of tert-butanol was introduced as an alternative to conventional freeze-drying to prepare high porosity aerogels from nanofibrillated cellulose (Sehaqui et al., 2011b). Due to the smaller polarity of this alcohol, the surface tension effects (capillary action) were less pronounced during the drying process.

The freezing points of most of the alcohols are much lower than that of water except for tert-butanol. Therefore, we postulated that less branched low-MW alcohols could be used as even more effective additives to prepare high performance controllable porous foams. In the present work, one of four C2-C4 alcohols such as ethanol, isopropanol, tert-butanol and n-butanol was added into NFC suspensions followed by freeze-drying. The objective was to control the ice crystal formation process, ultimately preparing the porous foams with a controlled cell structure and size. The microstructure, density, porosity, shrinkage, mechanical properties, and thermal properties of NFC foams were documented and explained, informing the formation mechanism of layered porous NFC foams by freeze-drying.

\section{Experimental section}

\subsection{Materials}

Nanofibrillated cellulose (NFC) (7.5 wt\% concentration, made from Pinus massoniane softwood pulp) was purchased from Ningbo ATMK li-ion Science \& Technology Ltd (Ningbo, China). Softwood pulp was pretreated by cellulase for $6 \mathrm{~h}$ at room temperature, at $1 \mathrm{wt} \%$ concentration. The fibrillation was carried out with high-pressure homogenization; the slurry was passed 10 times at a pressure of $100 \mathrm{Mpa}$. The slurry was finally obtained using a semi-industrial scale grinder (MKCA6-2 J) being operated at 1000rmp.

Ethanol, isopropanol, tert-butanol and n-butanol were purchased from Sinopharm Chemical Reagent Co., Ltd, China. All chemicals were of analytical grade and used as received.

\subsection{Preparation of NFC foams}


Alcohol/water/NFC suspensions with one of four alcohols (with $5 \mathrm{wt} \%$ concentration) were prepared by adding the designed amounts of water and alcohols to an aqueous NFC dispersion, which was stirred vigorously for $10 \mathrm{~min}$ at $2000 \mathrm{rpm}$. The selected low alcohol concentration does not alter the mostly aqueous nature of NFC suspensions - as shown in literature, this change occurs only at alcohol concentrations exceeding 15\% (Takaizumi and Wakabayashi, 1997). The resulting suspension was degassed in vacuum before being placed into an aluminum cup ( $40 \mathrm{~mm}$ in height and $70 \mathrm{~mm}$ in diameter). The thickness of these samples was near $2.5 \mathrm{~cm}$. In order to avoid macroscopic cracking that may be inflicted by the ensuing freeze-drying, all samples were pre-cooled at $4{ }^{\circ} \mathrm{C}$ overnight before they were frozen either in a freezer $\left(-18^{\circ} \mathrm{C}\right)$ or liquid N2 $\left(-196^{\circ} \mathrm{C}\right)$. They were then freeze-dried in a benchtop freeze-dryer equipped with a bulk tray dryer (Shanghai BILON Instrument Co., Ltd, China) at a dry ice sublimation temperature of $-55^{\circ} \mathrm{C}$ and a pressure of $0.10 \mathrm{mbar}$ for 7 days to remove solid ice. All samples were conditioned at $23^{\circ} \mathrm{C}$ and $50 \%$ relative humidity for $24 \mathrm{~h}$ before the tests described in the next section.

\subsection{Analysis}

Any measurement of those reported below was conducted in triplicate. To condense the table size, only the mean values are reported. The experimental variance did not exceed $5 \%$ except for maximum and minimum diameters.

\subsection{Microscopic observations and foam structure analysis}

A NFC suspension was spread onto a metal substrate using carbon tape, allowed to dry $48 \mathrm{~h}$ at room temperature and coated with a thin layer of gold. Prior to micro-structural analysis, all foams were vacuum dried at $50^{\circ} \mathrm{C}$ overnight, then frozen in liquid nitrogen, fractured with mechanical force, and then dried in vacuum. The samples were fixed on a metal substrate using carbon tape and the sample surface was coated with a thin layer of gold under vacuum. A Hitachi S-4800 scanning electron microscope operated at $3 \mathrm{kV}$ was used to capture images of the surface and cross-sections of both the original NFC and foams.

Free image analysis software Image $\mathrm{J}(\mathrm{NIH}$, Bethesda, Maryland, USA) was used to measure the mean cell area, cell wall thickness and cell diameter.

\subsection{Density and porosity}

The foam density was calculated from the sample weight divided by sample volume. The dimensions of NFC foam were measured with a digital Vernier caliper. The porosity was obtained from $1-\left[\rho^{*} / \rho s\right]$, where $\rho^{*}$ is the foam density and $\rho s$ is the so-called cell wall density. The "cell wall" density characteristic for a specific foam type specified under Results and Discussion was approximated as the theoretical density of the observed cell wall, $\rho t$, which was calculated from the densities of each of its constituents, $\rho$, and their weight fractions, Wi:

(1) 
The densities used in the calculation of pt were 1000 and $1500 \mathrm{~kg} \cdot \mathrm{m}-3$ for water and NFC, respectively (Gibson and Ashby, 1997).

\subsection{Shrinkage of NFC foams}

The foam shrinkage is the reduction of the mean diameter $(\mathrm{Dt}-\mathrm{D}) / \mathrm{Dt} \times 100 \%$ during freeze drying, where $\mathrm{Dt}$ is the diameter of the aluminum cup and $\mathrm{D}$ is the mean diameter along the height of the foam samples after freeze drying. The $\mathrm{Dt}$ and $\mathrm{D}$ were measured by a digital Vernier caliper.

\subsection{Compression tests}

The freeze-dried NFC foams were cut to about $2 \mathrm{~cm}$ samples of cubic geometry using a sharp blade for low-density foams. The compression tests were performed at room temperature using a tensile testing machine (AI-7000-NGD, GOTECH, Taiwan) with a load cell of $5 \mathrm{kN}$. The compression strain rate was set to $10 \% \cdot \min -1$. The Young's modulus value was calculated from the initial linear region of the stress-strain curves. The yield stress was measured as the stress at the intersection between the tangent line to the elastic region and the tangent line of the collapsed region. The energy absorbed by the foam was reported as the area below the stress-strain curve between $0 \%$ and $70 \%$ strain for all samples.'

\subsection{Thermal properties}

\subsubsection{Thermal conductivity measurements}

The thermal conductivity of NFC foams, which is expressed in units of $\mathrm{W} /(\mathrm{m} \cdot \mathrm{K})$, was measured according to ASTM C1113/C1113 M-09 by a TC 3000 apparatus (Xi'an Xiatech Electronic Technology Co. Ltd., China). The tested samples had dimensions of $40 \times 30 \times 10 \mathrm{~mm} 3$.

\subsubsection{Thermogravimetric analysis (TGA)}

The foam thermal stability was characterized by a thermogravimetric analyzer/differential scanning calorimeter (STA449 F3, NETZSCH, Germany). Samples with a mass of $3.0 \pm 0.5 \mathrm{mg}$ were placed in an alumina crucible, and then heated from $35^{\circ} \mathrm{C}$ to $800^{\circ} \mathrm{C}$ with a heating rate of $10 \mathrm{~K} / \mathrm{min}$ under a $50 \mathrm{~mL}$ min-1 nitrogen purge gas flow.

\subsubsection{BET nitrogen adsorption/desorption measurements}

An ASAP2460 Surface Area and Porosity Analyzer (Micromeritics Instrument Corp.) was used to measure the pore volume, specific surface area and pore size distribution of the foam samples. The minimum limit of specific surface area that this instrument can detect is $0.0001 \mathrm{~m} 2 / \mathrm{g}$ and the measured pore size is $3.5-5000 \AA$.

\section{Results and discussion}

\subsection{Microstructure of the foams}

NFC foams formed in the presence of different alcohols (5wt\%) were successfully (without collapse) prepared from the corresponding NFC suspensions by using the freeze-drying method. The FE-SEM 
micrographs of the side surfaces of the foams based on NFC are shown in Fig. 1, and the corresponding structural parameters are shown in Table 1.
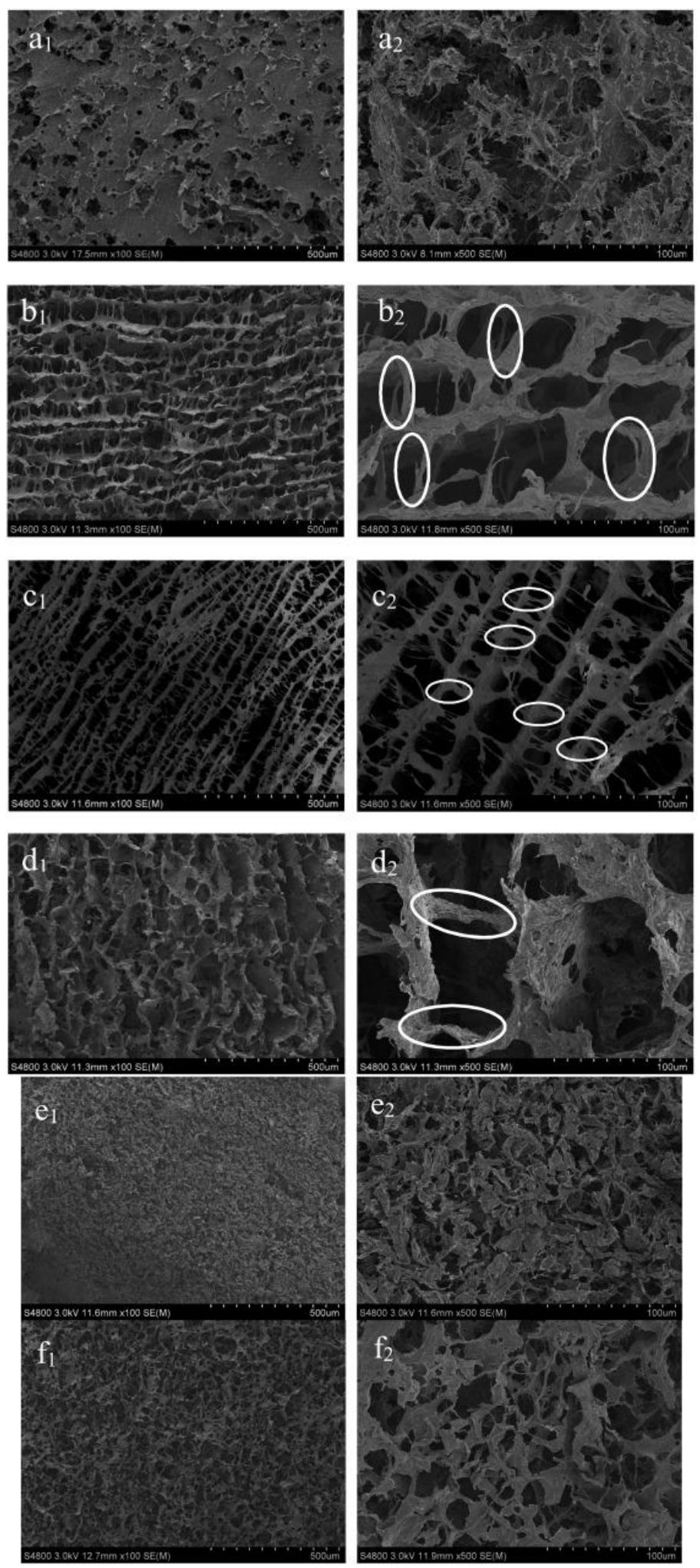
Fig. 1. Impact of the specific alcohol presence in the aqueous suspension on the microstructure of NFC foams at 1) $\times 100$ and 2) $\times 500$ (a1, a2 - blank sample (no alcohol); b1, b2 - freezing with ethanol at $-18^{\circ} \mathrm{C} ; \mathrm{c} 1, \mathrm{c} 2$ freezing with isopropanol at $-18^{\circ} \mathrm{C}$; d1, d2 - freezing with $\mathrm{n}$-butanol at $-18^{\circ} \mathrm{C}$; e1, e2 - freezing with tert-butanol ethanol at $-18^{\circ} \mathrm{C} ; \mathrm{f} 1, \mathrm{f} 2$ : - freezing with ethanol at $\left.-196^{\circ} \mathrm{C}\right)$.

Table 1. Pore structure parameters with different alcohols.

\begin{tabular}{llllllll} 
Alcohols & $\begin{array}{l}\text { Freezing } \\
\text { temperature } \\
\left({ }^{\circ} \mathbf{C}\right)\end{array}$ & $\begin{array}{l}\text { Mean cell } \\
\text { diameter } \\
\mathbf{L}_{\mathbf{1}}(\boldsymbol{\mu \mathbf { m } )}\end{array}$ & $\begin{array}{l}\text { Mean cell } \\
\text { diameter } \\
\mathbf{L}_{2}(\boldsymbol{\mu m})\end{array}$ & $\begin{array}{l}\text { Mean cell } \\
\text { area } \\
\left(\boldsymbol{\mu \mathbf { m } ^ { 2 } )}\right.\end{array}$ & $\begin{array}{l}\text { Mean cell } \\
\text { wall } \\
\text { thickness } \\
(\boldsymbol{\mu m})\end{array}$ & $\begin{array}{l}\text { Anisotropy } \\
\text { ratio } \\
\mathbf{R}=\mathbf{L}_{1} / \mathbf{L}_{2}\end{array}$ & $\begin{array}{l}\text { Cell density } \\
\text { (per cubic } \\
\text { centimeter) }\end{array}$ \\
\hline- & -18 & 14.4 & 7.98 & 83.5 & - & 1.81 & $1.24 \times 10^{8}$ \\
Ethanol & -18 & 68.1 & 47.3 & $3.23 \times 10^{3}$ & 2.46 & 1.44 & $4.89 \times 10^{6}$ \\
Isopropanol & -18 & 74.3 & 51.3 & $3.79 \times 10^{3}$ & 2.57 & 1.45 & $3.81 \times 10^{6}$ \\
n-Butanol & -18 & 90.0 & 60.7 & $4.77 \times 10^{3}$ & 2.73 & 1.48 & $3.04 \times 10^{6}$ \\
tert-Butanol & -18 & 8.65 & 5.50 & 40.9 & - & 1.57 & $5.72 \times 10^{8}$ \\
Ethanol & -196 & 19.2 & 11.8 & $2.72 \times 10^{2}$ & - & 1.63 & $3.47 \times 10^{8}$
\end{tabular}

The blank samples containing no alcohols showed a porous network structure with an irregular pore distribution (Fig. 1a). Contrasting these features, Fig. 1b-d show the foams prepared with ethanol, isopropanol and $\mathrm{n}$-butanol, respectively. All three samples exhibited highly porous structures with a layered honeycomb-like cellular texture featuring a well-defined "cell wall" between the layered cellular structures. The anisotropy ratio of all three samples was close to 1 , which means that the cell shape was near-spherical. Henceforth, we will call these materials "Type A" foams.

By contrast, the foam prepared with tert-butanol showed a uniform distribution of the pores with smaller pore diameters (Fig. 1e), but the pore shapes were irregular, with a higher anisotropy ratio (Table 1). Presumably, this change occurred because of the similarity of the freezing points of water $\left(0.0^{\circ} \mathrm{C}\right)$ and this particular alcohol $\left(25.7^{\circ} \mathrm{C}\right)$, so they could freeze as a whole instead of the prior separation of the additive from water, as for the rest of the alcohols.

To verify this assumption, we conducted an experiment when the foam was prepared by freeze-drying with ethanol at $-196^{\circ} \mathrm{C}$, to enable a similar near-simultaneous freezing of both alcohol and water. Indeed, it can be seen from Fig. $1 f$ that the layered cellular texture characteristic for the foam obtained with this alcohol at $-18^{\circ} \mathrm{C}$ did not appear, revealing instead a 3D network structure with a higher number of small pores. These observed qualitative features were confirmed by measuring the corresponding parameters (Table 1), i.e., pore diameters, areas and densities, the observed trends being similar to those obtained with tert-butanol at a much higher freezing temperature, thus corroborating our hypothesis. Henceforth, these two foams will be referred to as "Type B" materials. 
During freezing, the nucleated and growing ice crystals push out the adjacent NFC fibers, so they become separated by the ice crystals formed (Nireesha et al., 2013; Svagan et al., 2011). The subsequent drying preserves this layout to become the cell structure of the foams formed. Namely, the porous foam structure is a reverse copy of the ice crystal structure (Liu and Yan, 2014). As the ice crystals are sublimed, the layered cellular structure and "cell wall" are generated around the emerging voids.

The following explanation of the observed trends can be offered, which is consistent with the published literature. Although polar, inherently hydrophilic alcohols can blend uniformly with water, the freezing point of most alcohols is much lower than that of water. The liquid surface tension is reduced by alcohols, leading to the corresponding increase of the critical nucleation energy (Pan et al., 2011), which results in the reduction of the number of ice crystals formed, thus increasing the ice crystal size. When the freezing temperature is above the freezing point of a given alcohol (as for all cases except for tert-butanol at $-18^{\circ} \mathrm{C}$ and ethanol at $-196{ }^{\circ} \mathrm{C}$ ), water freezes while the alcohol remains in the liquid phase. This scenario is characteristic for the formation of Type A foams.

During freeze-drying, solvents evaporate leaving out the NFC structure, so the ice pre-existing crystal structure converts into the foam pore structure (Liu and Yan, 2014). As shown by Takaizumi (Takaizumi, 2005), pure water freezes out of $5 \%$ ethanol/water solutions until the ethanol concentration increases to $13 \%$ corresponding to the $\mathrm{EtOH} \times 17 \mathrm{H} 20$ clathrate. Apparently, similar phenomena are characteristic for any alcohol aqueous solutions, so the formation and growth of ice crystals push out any non-aqueous impurities, i.e., both the cellulose fibers and alcohol molecules. Then, the ultimate foam structure depends primarily on the combination of temperature and freezing point of the non-aqueous solvent component as shown for three different cases considered below.

According to these considerations, the dimensions of ice crystals are expected to be similar to the shape and size of the ultimately formed foam pores. This assumption is directly applicable to the first case, with the use of a higher freezing temperature $\left(-196^{\circ} \mathrm{C}\right)$ and non-branched alcohols. The well-known directionality of ice crystal formation (Deville, 2008; Deville et al., 2006; Liu and Yan, 2014) appears to explain the formation of layered structures (Fig. 1).

The pore size of the foams obtained with ethanol, isopropanol and n-butanol decreased in the order listed. A likely reason might be that the alcohol polarity decreases in this order as well while the molecular size increases. The higher polarity ethanol molecules readily form hydrogen bonds with free hydroxyl groups on the NFC fiber surface, this effect being further facilitated by their smallest size. This intermolecular bonding appears to enhance the phase separation, further pushing the impurities away from the ice crystals formed, so the latter grow to a larger volume. Thus, even though all Type A foams should exhibit similar physical properties, some minor differences are expected to be alcohol specific. 
The use of tert-butanol as an additive is expected to alter this process; this is the second case. Because the freezing point of tert-butanol is higher than that of water, freezing of its aqueous solution may occur under two scenarios. In the first of these scenarios, tert-butanol freezes first, followed by water. In this scenario assuming the thermodynamic control of ice nucleation (Deville et al., 2007), rather small pores would be formed in small amounts, due to the alcohol freezing, followed by the formation of large pores with a significant shrinkage, due to the subsequent water freezing.

The second possible scenario (occurring under kinetic control) assumes the simultaneous freezing of water and tert-butanol. This scenario is plausible due to a much higher percentage of water and its high miscibility with this alcohol. According to the earlier publications (Bevan Ott et al., 1979; Daoussi et al., 2011; Kasraian and DeLuca, 1995), when the tert-butanol content is less than 10\%, its molecules become wrapped around the water molecules to form the eutectic compounds (clusters). In addition to hindering the separation of alcohol and water during freezing, large amounts of water are thus consumed to form these clusters, which may effectively limit the growth of ice crystals (Nemoto et al., 2015). Due to a much smaller size of these dispersed eutectic inclusions than that of grown ice crystals, much smaller size and irregularly distributed pores are expected to be formed after the ice and alcohol sublimation.

Though both scenarios would yield small-size pores, just as observed, this scenario would yield consistently smaller pores. As the pores, indeed, appear to be consistently of a small size, the second scenario appears to be more plausible, although some minor alcohol/water separation may occur prior to freezing, during ice nucleation - so, these two scenarios complement rather than contradict each other. The observed anisotropic ratio being much lower than that in blanks is also consistent with the nearsimultaneous freezing with this alcohol, as the anisotropic ratio in blanks obtained with pure water is much higher. As a result, much smaller and more densely interspersed pores are expected to form, just as observed.

Similar kinetic considerations should be applied to freezing at $-196{ }^{\circ} \mathrm{C}$ in the presence of ethanol, the third case considered herein, as the freezing temperature becomes much lower than the freezing point of not just water but also any additive, e.g., ethanol, so the alcohol-NFC suspension is frozen near instantaneously as a whole. The freezing rate increases with lowering temperature, so kinetic control is expected for such a low temperature. Furthermore, the lower freezing temperature results in nucleation of more ice crystals than those freezing at $-18{ }^{\circ} \mathrm{C}$, so the growth rate of a particular crystal is limited. As a result, the subsequent drying yields rather small size and irregularly distributed pores, with no layered cellular structure. Thus, the freezing temperature is the other key factor controlling the foam microstructure, in addition to the alcohol freezing point and polarity.

\subsection{BET results and method validation}


The specific surface area of the foam sample made with $5 \%$ ethanol and $5 \%$ NFC solid content was measured by BET method to determine if BET is an effective method to characterize this type of cellulose foam material. Fig. 2 shows both the cumulative specific pore volume and the $\mathrm{dV} / \mathrm{dlog}$ (w) pore volume $(\mathrm{cm} 3 / \mathrm{g})$ distribution. Unfortunately, these data are not compatible with the SEM images (Fig. 1) showing much larger mesopores $>50 \mathrm{~nm}$. The measured BET pore area $(2.73 \mathrm{~m} 2 / \mathrm{g})$ is more than ten times greater than the estimated pore area from SEM images $(0.2 \mathrm{~m} 2 / \mathrm{g})$. It is concluded that BET measurements are not suitable for characterization of mesoporous samples, such as the cellulose foams that we made in this project. Presumably, most of the small pores measured by BET are those formed by fiber intercalation.

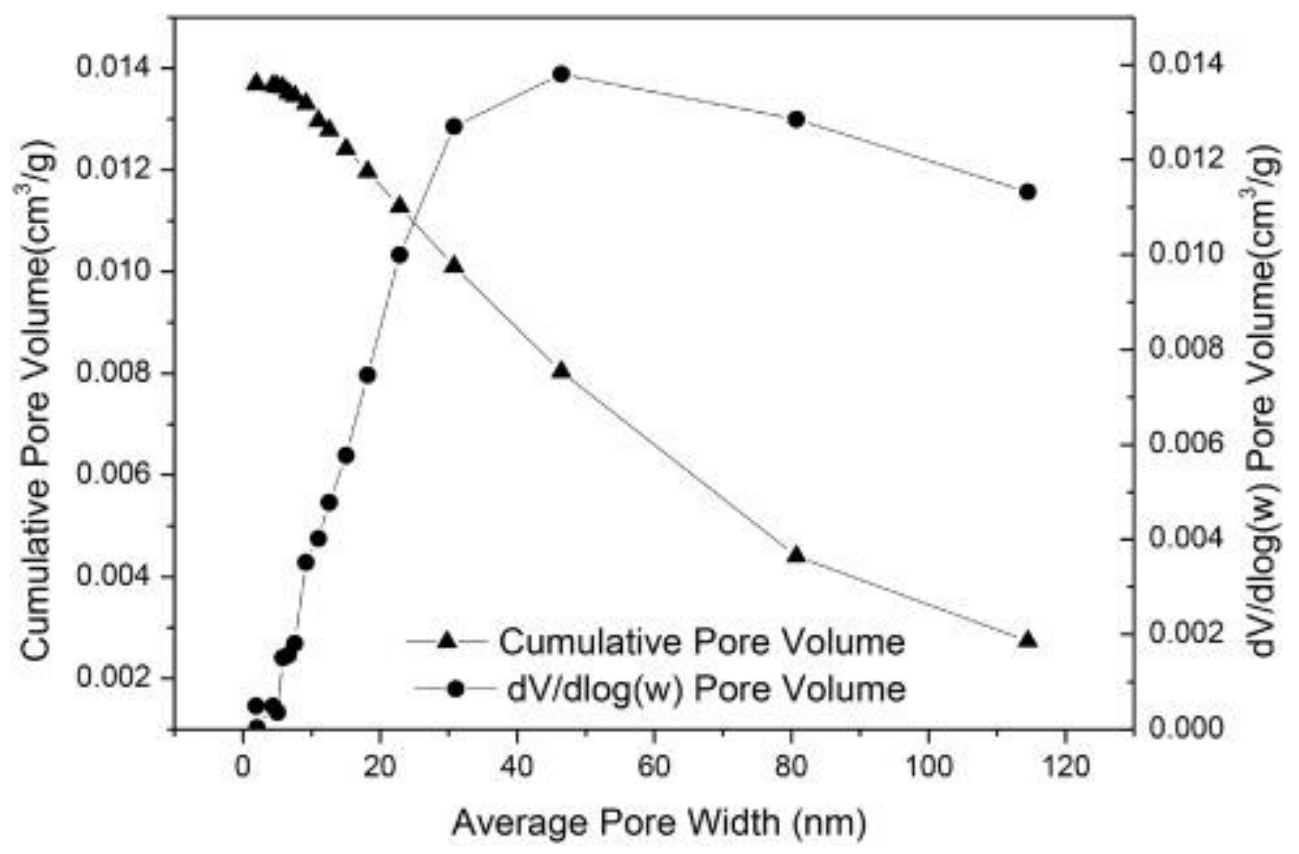

Fig. 2. BET data of the NFC-based foam materials with $5 \%$ ethanol content.

\subsection{Bulk properties of the foam formed: density, porosity and shrink rate}

The density, porosity and shrink rate of the obtained foams are summarized in Table 2 . The foam density ranged between 32.4 and $57.8 \mathrm{~kg} / \mathrm{m3}$, but the densities of the foams obtained in the presence of alcohols were consistently smaller than that of the blank samples. Consequently, the observed trend in material porosity was opposite: while the foam porosity ranged between $96.2 \%$ and $97.8 \%$, the porosities of all the foams prepared with alcohols, both Type A and B, were larger than that of the blank samples.

Table 2. Measured values of density, porosity, shrink rate and thermal conductivity of NFC foams.

\begin{tabular}{llllll} 
Alcohols & $\begin{array}{l}\text { Freezing } \\
\text { temperature }\left({ }^{\circ} \mathrm{C}\right)\end{array}$ & $\begin{array}{l}\text { Density } \\
\left(\mathrm{kg} \cdot \mathrm{m}^{-3}\right)\end{array}$ & $\begin{array}{l}\text { Porosity } \\
(\%)\end{array}$ & $\begin{array}{l}\text { Shrink rate } \\
(\%)\end{array}$ & $\begin{array}{l}\text { Thermal Conductivity } \\
(\mathrm{W} / \mathrm{m} \cdot \mathrm{K})\end{array}$ \\
\hline- & -18 & 57.8 & 96.1 & 21.4 & 0.046
\end{tabular}




\begin{tabular}{llllll} 
Alcohols & $\begin{array}{l}\text { Freezing } \\
\text { temperature }\left({ }^{\circ} \mathrm{C}\right)\end{array}$ & $\begin{array}{l}\text { Density } \\
\left(\mathbf{k g} \cdot \mathbf{m}^{-3}\right)\end{array}$ & $\begin{array}{l}\text { Porosity } \\
(\%)\end{array}$ & $\begin{array}{l}\text { Shrink rate } \\
(\%)\end{array}$ & $\begin{array}{l}\text { Thermal Conductivity } \\
(\mathrm{W} / \mathbf{m} \cdot \mathrm{K})\end{array}$ \\
\hline Ethanol & -18 & 34.1 & 97.6 & 4.9 & 0.041 \\
Isopropanol & -18 & 33.5 & 97.7 & 4.7 & 0.040 \\
tert-Butanol & -18 & 32.4 & 97.8 & 3.7 & 0.038 \\
n-Butanol & -18 & 32.7 & 97.8 & 4.3 & 0.039 \\
Ethanol & -196 & 33.1 & 97.8 & 3.7 & 0.036
\end{tabular}

Consistent with this trend, the shrink rates of the foams obtained with alcohols were drastically smaller than that of the blank samples. Even for the foam obtained at the freezing temperature being as low as $-196{ }^{\circ} \mathrm{C}$, the density, porosity and shrink rate of the foam were maintained at a similar level as for those foams that were produced at $-18^{\circ} \mathrm{C}$, as long as the process was conducted with the addition of an alcohol, e.g., ethanol.

Thus, the presence of alcohols appears to be an even more important factor than the solution freezing temperature in defining the foam physical properties, and this trend can be explained by molecular-scale considerations. Being hydrophilic, low-MW alcohols can be dispersed into an NFC suspension uniformly, while the polarity of alcohols is always smaller than that of water, and their freezing points are much lower than that of water (except for tert-butyl alcohol), so the ice crystal nucleation is significantly hindered. As a result, the movement of NFC fibers pushed away by growing ice crystals is hindered, as well as the foam shrinkage linked to this process. In turn, the reduced shrinkage yields a higher porosity, hence lower density. These considerations appear to explain the observed properties of Type A foams.

The Type B foams also exhibited reasonably low shrink rates. This observation is consistent with kinetic control, as the fiber movement would be minimized if freezing occurred as a whole. However, even if the kinetic control were not absolute, i.e., tert-butanol partially crystallized prior to water, the movement of NFC fibers would be limited during the alcohol crystallization and remain slow afterwards, as the ice crystals can only form and grow between the tert-butanol crystals.

So, similar to the rest of alcohols used in this study, the foam shrinkage was expected to be reduced, just as observed. In turn, it also resulted in a smaller density and larger porosity compared to the blank samples with no alcohols. It is of note that these considerations appear to explain the observed slight difference between the two Type $B$ foams considered in this study. While everything freezes nearinstantly at $-196{ }^{\circ} \mathrm{C}$, the case with tert-butanol at $-18^{\circ} \mathrm{C}$ is different by freezing some alcohol additive prior to water freezing.

\subsection{Thermal conductivity}


A lower thermal conductivity leads to a better insulation, so this parameter is important for foam characterization. Thermal conductivity measurements (Table 2 ) yielded no statistically significant difference among the preparations with different alcohols. Yet, the values obtained for Type B foams were the lowest, corroborating the trends discussed in the previous section. By contrast, the blank samples showed a higher thermal conductivity. These observed trends were expected, as low thermal conductivity is linked with high material porosity. Published research reported that the thermal conductivity is around 0.02-0.03 W/m·K for Polyurethane (PU) foams (Jelle, 2011; Wu et al., 1999), 0.2-0.5 for EPS (Jeong et al., 2009; Kan and Demirboğa, 2009; Zhang et al., 2017) and 0.04-0.05 for conventional cellulose insulation materials (Kymäläinen and Sjöberg, 2008). The obtained low values suggest applications of our foam materials for thermal insulation, although other, less expensive cellulosic materials show similar insulation properties. Perhaps, the potential applications of NFC-based foams should combine their low thermal conductivity with mechanical properties considered in the next section.

\subsection{Mechanical properties}

The mechanical properties of the foams prepared in the presence of different alcohols were investigated as well, due to their critical importance for foam characterization. The obtained stress-strain curves of NFC foams are presented in Fig. 3 while the corresponding numerical values are summarized in Table 3. The NFC foams exhibited ductile behavior and could be compressed to large strains (>90\%). NFC fibrils deform primarily by bending as fibers typically do in low density fiber networks. (Clyne et al., 2005) The ductility occurs because individual NFC nanofibers can bend to a very small radius of curvature. This, in turn, is a consequence of the small NFC fiber diameter in combination with a high fiber strength.

(Sturgeon, 1982) The stress-strain curves in Fig. 3 show a strain-hardening behavior occurring already at low strain values, although the yield stress cannot be measured accurately.

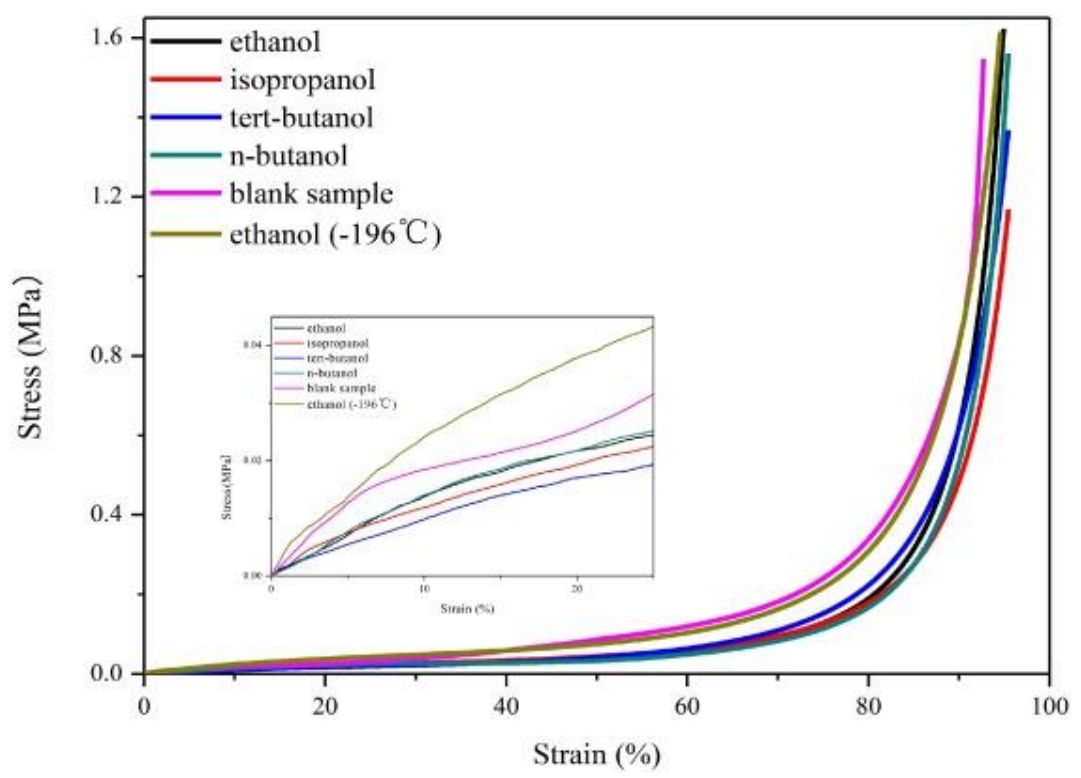

Fig. 3. Stress-strain curves of the obtained NFC foams. 
Table 3. Mechanical properties of the obtained NFC foams.

\begin{tabular}{llllll} 
Alcohols & $\begin{array}{l}\text { Freezing } \\
\text { temperature } \\
\left({ }^{\circ} \mathrm{C}\right)\end{array}$ & Density & $\begin{array}{l}\text { Young's } \\
\text { modulus } \\
(\mathrm{KPa})\end{array}$ & $\begin{array}{l}\text { Yield stress } \\
(\mathrm{KPa})\end{array}$ & $\begin{array}{l}\text { Energy absorption } \\
\left(\mathbf{K J} \cdot \mathbf{m}^{-3}\right)\end{array}$ \\
\hline- & -18 & 57.8 & 252.9 & 15.9 & 4.33 \\
Ethanol & -18 & 34.1 & 137.8 & 17.8 & 2.37 \\
Isopropanol & -18 & 33.5 & 148.9 & 14.1 & 2.31 \\
tert-Butanol & -18 & 32.4 & 155.1 & 14.9 & 2.33 \\
n-Butanol & -18 & 32.7 & 155.1 & 24.2 & 2.42 \\
Ethanol & -196 & 33.1 & 375.0 & 31.5 & 4.25
\end{tabular}

Compared to the blank samples, both energy absorption and Young's modulus were consistently smaller for those obtained with alcohols at $-18^{\circ} \mathrm{C}$, but both the linear elastic stages and yield plateau phases of their stress-strain curves were prolonged and yield stress remained similar. These parameters are characteristic for so-called "soft" foams (Wang et al., 2018). Consistent with this description, they could be compressed only once during the compression tests.

The foam mechanical properties are expected to be linked to its density, which, in turn, is defined by its shrinking behavior during freezing. Unexpectedly, even though the densities of the foams prepared with different alcohols were similar, the differences in their static compression mechanical properties, which were expected to be dependent on density, were found to be pronounced. In an attempt to elucidate the observed trends, we used the Gibson-Ashby model correlating the relative foam yield stress $\sigma^{*}$ and Young's modulus $\mathrm{Ef}^{\star}$, to the relative density of the obtained foams (relative to the density of the corresponding non-foamed cellulosic materials labeled with "s"), Eqs. (2) and (3):

The corresponding plot of of* vs. ( $\rho f / \rho)$ yielded no correlation, as shown for $\sigma f^{*}$ in Fig. 4. Not only this plot indicates no correlation with relative density, it actually shows that all of the foam samples obtained with alcohols have similar relative densities - yet some of them exhibit rather different yield strength values, thus pointing at the alternate explanation based on the foam type and structure. 


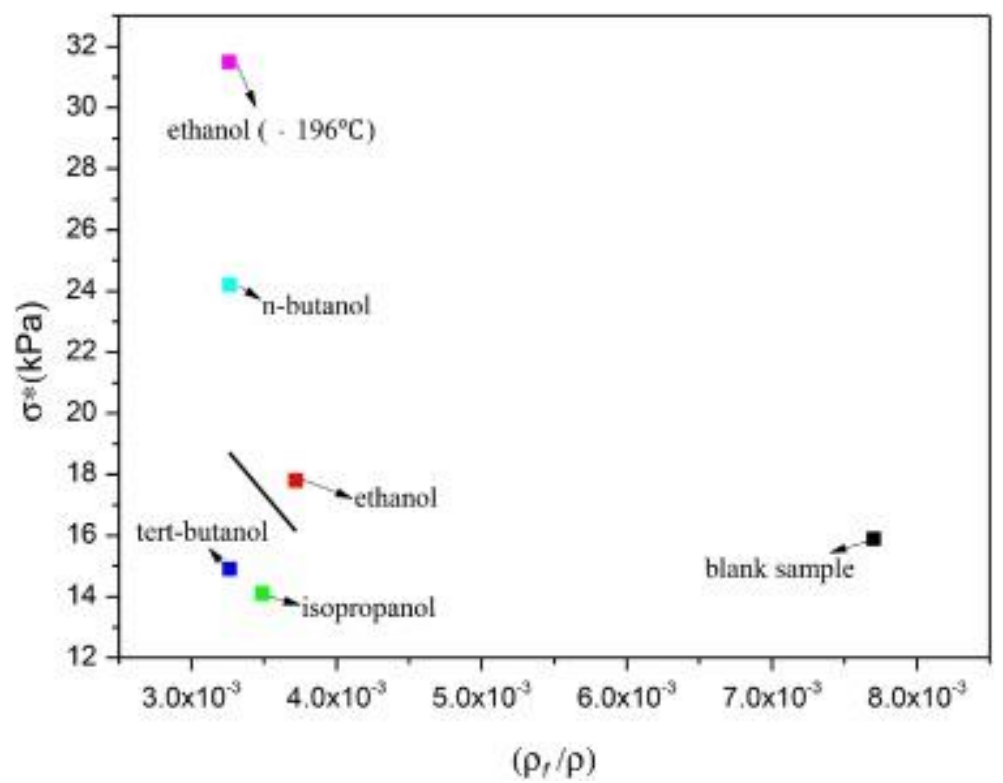

Fig. 4. Relationship between yield strength $\sigma^{*}$ and relative density $(\rho f / \rho)$ of the foams with different alcohols.

The most likely reason for this apparent contradiction is the above-discussed significant difference observed in the corresponding foam microstructure, cf. Table 1, as the foam mechanical properties are dependent on their pore structure (Svagan et al., 2011). Whenever the foams featured a regular layered honeycomb-like structure with a well-defined pore structure, i.e., any Type A foam (except for the nbutanol samples characterized by smaller pores), the corresponding yield strength, Young's modulus and energy absorption values were found to be smaller, as reflected in the numerical values listed in Table 3.

\subsection{Thermal analysis}

The TG curves of the obtained foams are shown in Fig. 5. All foams showed a similar thermal mass loss behavior, i.e., none of the added alcohols affected their thermal stability. This was expected, as the foam chemical structure, unlike certain physical properties, should be identical for all foams, as freeze-drying does not involve any chemical changes. 


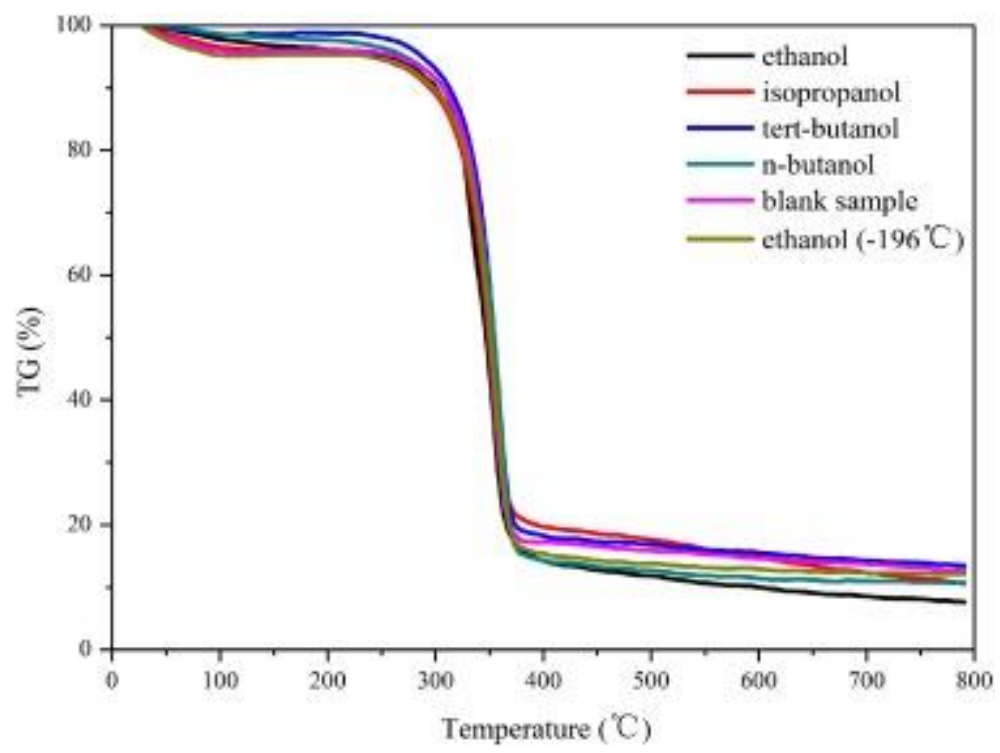

Fig. 5. TG analysis curves of NFC foams.

The mass loss below $200^{\circ} \mathrm{C}$ should be ascribed to water evaporation. The thermal decomposition of foams started occurring between $310-380^{\circ} \mathrm{C}$, and the maximum heat loss was observed when at 350 $357^{\circ} \mathrm{C}$; the weight loss rate was more than $70 \%$. The heat loss in this stage was due to mild pyrolysis of cellulose, resulting in the formation of non-combustible gas (CO2) and other volatile compounds of a relatively low molecular weight. At temperatures above $380{ }^{\circ} \mathrm{C}$, cellulose was carbonized to gradually form elemental carbon with a graphite-like structure, so the mass loss rate decreased.

\section{Conclusions}

The obtained results suggest that the foam structure can be effectively controlled by varying either the alcohol or freeze-drying temperature. The foams prepared with ethanol, isopropanol and $n$-butanol at a relatively high freeze-drying temperature, $-18^{\circ} \mathrm{C}$, significantly exceeding the alcohol freezing point, exhibited highly porous structures with a layered honeycomb-like cellular texture featuring a well-defined "cell wall" between the layered hierarchical structures. We called these materials "Type A" foams assuming the thermodynamic control of their formation. By contrast, the foam obtained under similar conditions with tert-butanol featured irregularly shaped pores, although it had higher number pores of a much smaller size. The foams prepared by ethanol freezing at $-196{ }^{\circ} \mathrm{C}$ revealed similar features. We classified these two materials as "Type B" group assuming the kinetic control of their formation. The microscopic observations translated into the foam physical properties. Of those, the most important was the remarkable reduction of shrinkage, particularly in Type A materials, compared to the blanks with no alcohols. Type A foams turned out to be "softer" than Type B, i.e., showing more of elasticity than strength, apparently due to their different pore size and structure. The hierarchical structure of these foams suggests applications in templates, filters, etc. 
This exploratory study suggests potential of using the NFC foams prepared by freeze-drying in the presence of alcohols as structural insulation materials, templates for inorganic nanoparticle synthesis, energy absorption applications, e.g., use in packing materials, and even applications based on the material porous structure such as filtration, adsorption, drug delivery and catalysis.

\section{Acknowledgements}

This research project was supported by the National Key Research and Development Plan of China (2017YFB0307901), Key Research and Development Projects of Shaanxi Province (2017ZDXM-SF-090), State Key Laboratory of Pulp and Paper Engineering open foundation (Grant No. 201505) and Key research planning program of key laboratory from education department of Shaanxi Province (17JS015). We would like to express our special thanks professor Adriaan vanHeiningen at the University of Maine for his excellent comments and help.

\section{References}

Ali and Gibson, 2013 Z.M. Ali, L.J. Gibson

The structure and mechanics of nanofibrillar cellulose foams

Soft Matter, 9 (2013), pp. 1580-1588, 10.1039/C2SM27197D

Bevan Ott et al., 1979 J. Bevan Ott, J. Rex Goates, B.A. Waite

(Solid + liquid) phase equilibria and solid-hydrate formation in water + methyl, + ethyl, + isopropyl, and + tertiary butyl alcohols

J. Chem. Thermodyn., 11 (1979), pp. 739-746, 10.1016/0021-9614(79)90005-3

Clyne et al., 2005 T.W. Clyne, A.E. Markaki, J.C. Tan

Mechanical and magnetic properties of metal fibre networks, with and without a polymeric matrix Compos. Sci. Technol., 65 (2005), pp. 2492-2499, 10.1016/j.compscitech.2005.05.037

Daoussi et al., 2011 R. Daoussi, E. Bogdani, S. Vessot, J. Andrieu, O. Monnier

Freeze-drying of an active principle ingredient using organic co-solvent formulations: influence of freezing conditions and formulation on solvent crystals morphology, thermodynamics data, and sublimation kinetics

Dry Technol., 29 (2011), pp. 1858-1867, 10.1080/07373937.2011.569624

Dash et al., 2012 R. Dash, Y. Li, A.J. Ragauskas

Cellulose nanowhisker foams by freeze casting

Carbohydr. Polym., 88 (2012), pp. 789-792, 10.1016/j.carbpol.2011.12.035

De France et al., 2017 K.J. De France, T. Hoare, E.D. Cranston

Review of hydrogels and aerogels containing nanocellulose

Chem. Mater. (2017), 10.1021/acs.chemmater.7b00531

Deville, 2008 S. Deville

Freeze-casting of porous ceramics: a review of current achievements and issues

Adv. Eng. Mater. (2008), pp. 155-169, 10.1002/adem.200700270

Deville, 2010 S. Deville 
Freeze-casting of porous biomaterials: structure, properties and opportunities

Materials (Basel), 3 (2010), pp. 1913-1927, 10.3390/ma3031913

Deville, 2013 S. Deville

Ice-templating, freeze casting: beyond materials processing

J. Mater. Res, 28 (17) (2013), pp. 2202-2219, 10.1557/jmr.2013.105

Deville et al., 2006 S. Deville, E. Saiz, R.K. Nalla, A.P. Tomsia

Freezing as a path to build complex composites

Science, 80 (311) (2006), pp. 515-518, 10.1126/science.1120937

Deville et al., 2007 S. Deville, E. Saiz, A.P. Tomsia

Ice-templated porous alumina structures

Acta Mater., 55 (2007), pp. 1965-1974, 10.1016/j.actamat.2006.11.003

Deville et al., 2009 S. Deville, E. Maire, G. Bernard-Granger, A. Lasalle, A. Bogner, C. Gauthier, J.

Leloup, C. Guizard

Metastable and unstable cellular solidification of colloidal suspensions

Nat. Mater., 8 (2009), pp. 966-972, 10.1038/nmat2571

Dlouhá et al., 2014 J. Dlouhá, L. Suryanegara, H. Yano

Cellulose nanofibre-poly(lactic acid) microcellular foams exhibiting high tensile toughness

React. Funct. Polym., 85 (2014), pp. 201-207, 10.1016/j.reactfunctpolym.2014.07.016

Frech, 2002 C.B. Frech

Green plastics: an introduction to the New science of biodegradable plastics (Stevens, E.S.)

J. Chem. Educ., 79 (2002), p. 1072, 10.1021/ed079p1072.1

Gibson and Ashby, 1997 L.J. Gibson, M. Ashby

Cellular Solids, Structure and Properties

Cambridge University Press (1997), 10.1557/mrs2003.79

Jelle, 2011 B.P. Jelle

Traditional, state-of-the-art and future thermal building insulation materials and solutions -

properties, requirements and possibilities

Energy Build. (2011), 10.1016/j.enbuild.2011.05.015

Jeong et al., 2009 Y.S. Jeong, H.J. Choi, K.W. Kim, G.S. Choi, J.S. Kang, K.S. Yang

A study on the thermal conductivity of resilient materials

Thermochim. Acta, 490 (2009), pp. 47-50, 10.1016/j.tca.2009.02.015

Kan and Demirboğa, 2009 A. Kan, R. Demirboğa

A new technique of processing for waste-expanded polystyrene foams as aggregates

J. Mater. Process. Technol., 209 (2009), pp. 2994-3000, 10.1016/j.jmatprotec.2008.07.017

Kasraian and DeLuca, 1995 K. Kasraian, P.P. DeLuca

Thermal analysis of the tertiary butyl alcohol-water system and its implications on freeze-drying

Pharm. Res.: Off. J. Am. Assoc. Pharm. Sci., 12 (1995), pp. 484-490, 10.1023/A:1016233408831

Klemm et al., 2005 D. Klemm, B. Heublein, H.P. Fink, A. Bohn

Cellulose: fascinating biopolymer and sustainable raw material 
Angew. Chemie Int. Ed. (2005), 10.1002/anie.200460587

Kymäläinen and Sjöberg, 2008 H.R. Kymäläinen, A.M. Sjöberg

Flax and hemp fibres as raw materials for thermal insulations

Build. Environ., 6 (2008), 10.1016/j.buildenv.2007.03.006

Lee and Deng, $2011 \mathrm{~J}$. Lee, Y. Deng

The morphology and mechanical properties of layer structured cellulose microfibril foams from ice-templating methods

Soft Matter, 7 (2011), p. 6034, 10.1039/c1sm05388d

Li and Ragauskas, 2012 Y. Li, A.J. Ragauskas

Ethanol organosolv lignin-based rigid polyurethane foam reinforced with cellulose nanowhiskers RSC Adv., 2 (2012), p. 3347, 10.1039/c2ra00646d

Li et al., 2012 W.L. Li, K. Lu, J.Y. Walz

Freeze casting of porous materials: review of critical factors in microstructure evolution Int. Mater. Rev., 57 (2012), pp. 37-60, 10.1179/1743280411Y.0000000011

Liu and Yan, 2014 G. Liu, Y. Yan

Research progress of porous ceramics produced by freeze casting technique

J. Inorg. Mater., 29 (6) (2014), pp. 571-583, 10.3724/SP.J.1077.2014.13506

Malainine et al., 2005 M.E. Malainine, M. Mahrouz, A. Dufresne

Thermoplastic nanocomposites based on cellulose microfibrils from Opuntia ficus-indica parenchyma cell

Compos. Sci. Technol., 65 (2005), pp. 1520-1526, 10.1016/j.compscitech.2005.01.003

Martoïa et al., 2016 F. Martoïa, T. Cochereau, P.J.J. Dumont, L. Orgéas, M. Terrien, M.N. Belgacem

Cellulose nanofibril foams: links between ice-templating conditions, microstructures and mechanical properties

Mater. Des., 104 (2016), pp. 376-391, 10.1016/j.matdes.2016.04.088

Nakagaito and Yano, 2004 A.N. Nakagaito, H. Yano

The effect of morphological changes from pulp fiber towards nano-scale fibrillated cellulose on the mechanical properties of high-strength plant fiber based composites

Appl. Phys. A: Mater. Sci. Process., 78 (2004), pp. 547-552, 10.1007/s00339-003-2453-5

Nakamatsu et al., 2006 J. Nakamatsu, F.G. Torres, O.P. Troncoso, Y. Min-Lin, A.R. Boccaccini

Processing and characterization of porous structures from chitosan and starch for tissue engineering scaffolds

Biomacromolecules, 7 (2006), pp. 3345-3355, 10.1021/bm0605311

Nemoto et al., 2015 J. Nemoto, T. Saito, A. Isogai

Simple freeze-drying procedure for producing nanocellulose aerogel-containing, highperformance air filters

ACS Appl. Mater. Interfaces, 7 (2015), pp. 19809-19815, 10.1021/acsami.5b05841

Nireesha et al., 2013 G. Nireesha, L. Divya, C. Sowmya, N. Venkateshan, M. Niranjan Babu, V. Lavakumar 
Lyophilization/freeze drying -an review

ljntps, 3 (2013), pp. 87-98

O'Brien et al., 2004 F.J. O'Brien, B.A. Harley, I.V. Yannas, L. Gibson

Influence of freezing rate on pore structure in freeze-dried collagen-GAG scaffolds

Biomaterials, 25 (2004), pp. 1077-1086, 10.1016/S0142-9612(03)00630-6

Pan et al., 2011 D. Pan, L.M. Liu, B. Slater, A. Michaelides, E. Wang

Melting the ice: on the relation between melting temperature and size for nanoscale ice crystals ACS Nano, 5 (2011), pp. 4562-4569, 10.1021/nn200252w

Samir et al., 2004 M.A.S.A. Samir, F. Alloin, M. Paillet, A. Dufresne

Tangling effect in fibrillated cellulose reinforced nanocomposites

Macromolecules, 37 (2004), pp. 4313-4316, 10.1021/ma035939u

Sehaqui et al., 2010 H. Sehaqui, M. Salajková, Q. Zhou, L.A. Berglund

Mechanical performance tailoring of tough ultra-high porosity foams prepared from cellulose I

nanofiber suspensions

Soft Matter, 6 (2010), p. 1824, 10.1039/b927505c

Sehaqui et al., 2011a H. Sehaqui, Q. Zhou, L.A. Berglund

High-porosity aerogels of high specific surface area prepared from nanofibrillated cellulose (NFC)

Compos. Sci. Technol., 71 (2011), pp. 1593-1599, 10.1016/j.compscitech.2011.07.003

Sehaqui et al., 2011b H. Sehaqui, Q. Zhou, L.A. Berglund

Nanostructured biocomposites of high toughness-a wood cellulose nanofiber network in ductile hydroxyethylcellulose matrix

Soft Matter, 7 (2011), p. 7342, 10.1039/c1sm05325f

Sturgeon, 1982 J.B. Sturgeon

Introduction to composite materials

Composites (1982), 10.1016/0010-4361(82)90158-6

Svagan et al., 2007 A.J. Svagan, M.A.S. Azizi Samir, L.A. Berglund

Biomimetic polysaccharide nanocomposites of high cellulose content and high toughness

Biomacromolecules, 8 (2007), pp. 2556-2563, 10.1021/bm0703160

Svagan et al., 2008 A.J. Svagan, M.A.S.A. Samir, L.A. Berglund

Biomimetic foams of high mechanical performance based on nanostructured cell walls reinforced by native cellulose nanofibrils

Adv. Mater., 20 (2008), pp. 1263-1269, 10.1002/adma.200701215

Svagan et al., 2010 A.J. Svagan, P. Jensen, S.V. Dvinskikh, I. Furó, L.A. Berglund

Towards tailored hierarchical structures in cellulose nanocomposite biofoams prepared by freezing/freeze-drying

J. Mater. Chem., 20 (2010), p. 6646, 10.1039/c0jm00779j

Svagan et al., 2011 A.J. Svagan, L.A. Berglund, P. Jensen

Cellulose nanocomposite biopolymer foam-hierarchical structure effects on energy absorption

ACS Appl. Mater. Interfaces, 3 (2011), pp. 1411-1417, 10.1021/am200183u 
Takaizumi, 2005 K. Takaizumi

A curious phenomenon in the freezing-thawing process of aqueous ethanol solution

J. Solut. Chem., 34 (2005), pp. 597-612, 10.1007/s10953-005-5595-6

Takaizumi and Wakabayashi, 1997 K. Takaizumi, T. Wakabayashi

The freezing process in methanol-, ethanol-, and propanol-water systems as revealed by

differential scanning calorimetry

J. Solut. Chem., 26 (1997), pp. 927-939, 10.1007/BF02768051

Wang et al., 2006 L. Wang, Y. Zhang, P. Gao, D. Shi, H. Liu, H. Gao

Changes in the structural properties and rate of hydrolysis of cotton fibers during extended enzymatic hydrolysis

Biotechnol. Bioeng., 93 (2006), pp. 443-456, 10.1002/bit.20730

Wang et al., 2018 G. Wang, G. Zhao, G. Dong, Y. Mu, C.B. Park, G. Wang

Lightweight, super-elastic, and thermal-sound insulation bio-based PEBA foams fabricated by high-pressure foam injection molding with mold-opening

Eur. Polym. J., 103 (2018), pp. 68-79, 10.1016/j.eurpolymj.2018.04.002

Wu et al., 1999 J.-W. Wu, W.-F. Sung, H.-S. Chu

Thermal conductivity of polyurethane foams

Int. J. Heat Mass Transf., 42 (1999), pp. 2211-2217, 10.1016/S0017-9310(98)00315-9

Zhang et al., 2017 H. Zhang, W.Z. Fang, Y.M. Li, W.Q. Tao

Experimental study of the thermal conductivity of polyurethane foams

Appl. Therm. Eng., 115 (2017), pp. 528-538, 10.1016/j.applthermaleng.2016.12.057 